\title{
Possibility of Situational Methodology
}

Marina G. Rumyantseva*1, Konstantin I. Solodov ${ }^{2}$

${ }^{1,2}$ Kazan Federal University, Institute of Social and Philosophical Sciences and Mass Communications, 420008,

Russian Federation, Kazan, Kremlevskayast., 18,

Email: margrum@yandex.ru, turigiuliano27@gmail.com

Received: 21st October 2017 Accepted: 16th November 2017, Published: 31st December 2017

\begin{abstract}
The article is devoted to understanding the boundaries and possibilities of applying situational methodology in the scientific studies of various orientations. The methodological principles used in this study are based on a dialectical methodology of the formation and development of a new, existentialist situation concept, presented in the studies and contextual analysis of K. Jaspers. It is argued the insufficiency of reducing the situation to a coincidence of circumstances, to instability and fluidity outside the connection with the past and the future, outside the situation subject, which centers it in a single whole. It is identified the boundaries of applying the situational methodology, due to the fact of the heterogeneity of the situations themselves, the subjectivism of interpreting their significance for predicting the future state of the system, the inadequacy of the formal and logical tools for analyzing situations and the possibility of using other types of logics. It is concluded that it is necessary to extrapolate the available range of possibilities for the future, taking into account the understanding of the goals of the situation subject, personal contribution to the transformation of circumstances that require an understanding of the meanings of human activity that go beyond the pragmatic solution of the immediate tasks dictated by the situation. It is stated the suitability of this approach, first of all, for the areas related to the social and humanitarian knowledge and social practice.
\end{abstract}

Keywords: Situation, Situational Approach, Methodology, Socio-Humanitarian Cognition, Subject.

\section{Introduction}

The situational approach to cognition has become a fairly common technique in the modern social and humanitarian practices. At the same time, it often does not go beyond the rhetoric, is located on the territory of everyday understanding of the term "situation", as a result it does not become the subject of study of the methodologists and is accordingly applied or postulated uncritically, beyond understanding its capabilities and boundaries.

Practical results achieved on the path of intuitive application of the situational approach in education, management, psychology, economics, etc., do not give grounds to believe that this approach is really consciously applied [1].

All this raises the question of the need to analyze the opportunities, which are situational according to their research methodology, as well as the boundaries in which it can exist and work.

\section{Methods}

The methodological basis for studying the situational approach is a set of various methods used in the social and humanitarian knowledge. It is used the contextual analysis, the comparative method, a number of social and humanitarian methods that enable us to identify the ways of linking the objective and subjective factors of development and awareness of the situation, its use for the specified purposes, forecasting the consequences of activities within the situation and beyond it. The situation is viewed from the point of view of its connection with a person who makes sense in a coincidence of circumstances, and thereby shapes both the situation itself and possible ways of resolving the underlying imbalance between the subjective values and intentions, as well as the objective performance results.

\section{Results}

As the research result, the authors have come to the conclusion that the situational methodology is possible, but is in the making. Departure from the situation connection with the circumstances is the first step towards the formation of a system of principles on which a situational approach can be built. A person (human) is in the center of the situation. This circumstance makes a situational methodology possible in the field of research and practices associated with it.

\section{Discussion}

K. Jaspers was one of the first scientists, who used the term "situation" to analyze the formation of new trends in the spiritual state of the society of the XX century [2]. It is this author and his analysis of the spiritual time situation that we take as a starting point of reflection on the situational methodology and the possibilities of its application. The result of the first test, carried out by Jaspers, can be called a feeling of the situation totality and the boundless possibilities of substituting a number of other, habitual and wellformed ones, by this term. In essence, the situation became a characteristic of a set of factors established that changed the human position in society and in the world. They include the technology development, which led to a fatal self-confidence of people, and the development of public institutions that made the society organized to the limit of human possibilities to exercise his freedom, and the subsequent growth of irresponsibility, the reduction of mutual trust, and the 
formation of a "black hole" of the masses... As a result, a proud and free human, confident in his abilities, "arrogant" in his impulse transforming all and the whole, suddenly finds himself in a position strangely illogical in terms of his intentions - he is helpless and alone.

Obviously, the enumeration of factors that have developed here and now, the diagnosis of the consequences of their wreath can claim a description, but hardly an analysis. In this case, the use of the term "situation" does not go beyond its usual ordinary interpretation and cannot make this term and the approach associated with it a candidate for a new cognition instrument. In general, this superficiality can be found, for example, in a number of educational practices [3], where the term is the recognition of variability of the conditions in which the educational process and the call for a rapid response to them take place. A combination of the already known methods with a noncritical addition of the term "situation" to their notion can be found in the psychological studies [4]. Similarly, it is possible to interpret the attempts of some naturalists to use this term as a tool in analyzing single, unique phenomena [5], when one can speak not only about situational, but a multifactorial approach.

At the same time, a persistent use of the term "situation" in the scientific, social and humanitarian studies, resulting in the emergence of such a phenomenon as the situational movement [6] and even the proclamation of the "Situational Movement Manifesto" [7] suggests that this term is interpreted by the modern philosophy with a meaning somewhat different from the set of factors. Let us see what this Manifesto offers us. The distinctive features of the situation are the dynamism of replaceable states, the probabilistic nature of qualitative changes, the multifactor determination, and the small predictability of the dominant factor's nomination. Accordingly, it is proposed to consider mobility, randomness, uncertainty, blurring of boundaries, factor equivalence, polyvariety, pluralism as the most important characteristics of the situational understanding of the world [7]. As we can see, there is not a word about the coincidence of circumstances here. But if we look closely at the characteristics given, the emphasis is made on them. Certainly, the characteristics given are extended. It would be a stretch to reduce them only to the circumstances, and, nevertheless... There is an adequate picture of the modern perception of reality with its dynamism, kaleidoscopy, contradictory combination of incongruous, unpredictable consequences, reality, in which there is no connecting rod, and therefore everything goes haywire. But what if we just do not see this rod? Perhaps, conventional to the tradition stability, we are looking for it not where it really is? What if it is just necessary to change the angle of view?

In any way, it is difficult to create an instrument of cognition and practical activity from these characteristics. They are descriptive. And we have the task of examining the possibilities of situational methodolo- gy, which requires the identification of regularities ordering chaos.

In fact, the very coincidence of circumstances can be regarded not so much as a fortuitous state, but as a certain pattern. But this pattern is not manifested. The situation uncertainty is only an appearance that exists as something that is not captured by thought. The pattern is obscured by a lively response to it, the need for reaction, an emotional experience. It is a challenge. A challenge to someone who is inside. However, it cannot be imagined from the inside. It can be experienced. There is no coincidence that the term "situation" is used by Jaspers to characterize the crisis and fracture, accompanied by a sense of loss and hopelessness. Outside of common meanings, roots, goals, certain definite spiritual landmarks, a person discovers only the contradictions of different "I", different value systems, and follows the path of least resistance - to the satisfaction of immediate needs. A person loses himself in the absence of understanding what he should be. He has only a lonely existence. And it is no accident that the question of the human essence is a pseudo-problem. The crisis removed this problem, it is impossible to understand even the superficiality of life in its conditions. The ideology, which is designed to identify the human goals, to express an attitude toward the world, to unite people by a common trickle becomes, according to Jaspers, sophistry. It does not lead, does not clarify, does not collect. It follows the mass, adapts to it and eventually turns into a false consciousness.

The crisis breaks the time (the time connection has broken up) and explodes the space. There is no past or future, there are only urgent "now" and "here". And indeed, the remnants, traces of the past come to the fore as unique and individual and as a spectrum of opportunities yet not implemented. They create the impression of a heap of accidents, unpredictability, even absurdity of everything that is happening.

With this reading, the situational approach is an attempt to think of a certain existing whole from the outside, fixing its crisis nature at the moment. And the term "situation" denotes here more than a confluence of circumstances. This is a field of crisis, in which the neutral earlier circumstances developed into a critical contradiction. In this case, the situational approach can become an analysis tool. It was the work demonstrated by Jaspers.

Crisis is the space of stratification of various ways of finding solutions. Accordingly, it emerges a probabilistic nature of possible development of any situation. The probabilistic nature of the ways out of the crisis sets the need to identify some basic grounds that organize chaos, a rod that allows regulating integrity to the situational analysis.

Obviously, the circumstances become some kind of holistic situation, provided that we see a certain meaning in them. Due to comprehension, randomness turns into regularity, and a situation becomes an event [8]. Or it does not become. The situation is a possible breakthrough to being, to the world of absolute values [9], lost by human, but necessary to him. 
Escape from being is a catastrophe indeed. Where the existence has been easily built according to the Truth of God, where the transcendental foundation has been seen for its existence previously, it is now being constructed only the existence not provided with being the momentary, vanity, petty existence. A human loses his connection with the metaphysical vision of the world, the ontological foundations of his existence. He is not connected in his thoughts with the beyond, eternal, ideal things, capable of making his life really meaningful. The human exists, but is not at being. Deprived of Being, he is forced to exist without foundation. He exists without foundation; he deprives himself of Being. And at the same time being is a person himself, because this is his design, he is the author of the picture of the world and he bears his share of responsibility for this world. According to Jaspers, payment means that a person ceases to be something and becomes nothing. The situational approach is appropriate here as highlighting the discrepancy and contradiction between present and proper, goals and meanings and analyzing the intent to implement the meanings and values, in a specific refraction through the goals and means of achieving them.

But, giving a meaning, we already change the situation. It is created by us. The situation is interesting by what happens at the boundary of the subjective and objective; it is a certain range of their synthesis. Moreover, the situational approach is focused on a person, comprehending himself and the world, snatching a certain qualitative stable integrity in a bizarre combination of heterogeneous factors precisely because of their penetration with meanings. Although a modern human has obvious problems with the meanings. Life acceleration makes the impressions superficial, does not enable to stop and reflect, raises requirements to simultaneous coverage of a set without possibility to notice and seize unity. A technocratic roll in the perception of self and the world, narrows the possibilities of comprehension. The meaning is associated with the use, efficiency, success... Of course, this is important. But there is no person with his spiritual quest and problems. There is no border between human and the world. The world turned out to be disproportionate to the person trying to comprehend it, and the person slowly leaves it. Even without noticing this. Leave is covered by the term "situation" in its general and superficial understanding.

In this regard, it is important that the "situation" is a language element, and not the reality itself. We give it a name. And we can hide behind it, taking off all responsibility for what is happening. It often happens when we feel some deficit of reflexive thought. The name becomes false. Otherwise, we manage to isolate the situation in the fluidity of what is happening, stopping or at least slowing down the course of events by an effort of thought. This is about awareness/unconsciousness about the situation. Cognitive situations indicate opportunities that can be implemented. It is in a cognitive situation that a person who is able to set goals and assume responsibility, becomes a co-author, he changes the situation just by its comprehension. The situation in which people are unconscious is simply uninteresting, it is too banal for thought, does not become an object of cognition, does not give grounds for posing a question about the situational approach. It consists in trying to find a tool to denote a subjective emphasis on the random, which is a manifestation of the necessary in fact, to the indefinite, which is supplemented by a certain in reality, to a unique, which would not be so, if there have been no recurring one.

At the same time, the situation is a meeting of the past, present and future held together by meaning. The situation is a definite point in its movement, in which many tendencies coming from the past are tied down, which requires disclosure of its historical background. The logic of developing the spiritual situation has enabled Jaspers to see those ideas that, being enthusiastically received in the past, lead to today's collapse: the ideologists and philosophers did not proclaim free human development without religion, depriving him of the possibility of touching eternity, unconditional and absolute? In this case, the situational approach requires a comprehensive analysis of trends coming from the past and forming a picture of the future, emerging from the chronotope of the present. The situation is only a form of life in which a particular person turns out to be. It is time to understand yourself and your role in changing the world through changing the situation. This is the space of his action or inaction. And understanding the situations, solving the situations, getting out of them is the task of a person who knows and changes the world. In this regard, the situational approach differs from the systemic or structural-functional analysis. Paradoxical as it may be, he requires leaving the momentary, randomness, instability, the bizarre game of multidirectional forces into the field of stable bases, which allow connecting time with meanings. A person responsible for the situation is at the center of this approach [10].

The situational approach is a delicate procedure for choosing the best means. The vision of the whole "today" presupposes an understanding of the goals related to "tomorrow". It should also form a specific strategy, including the difficult task of seeing the future, as a certain tactic element. Extrapolation of the available spectrum of opportunities for the future implies a clear definition of goals, and not in the narrowly pragmatic sense of the word.

The situational approach should be considered (of course, not in the natural-science field) as an opportunity to penetrate into that area, where the comprehension of activity circumstances occurs, making a personal contribution to the transformation of circumstances that is unobtainable by the usual methods of scientific knowledge. To a large extent this is the result of the work of intuition, which becomes an important factor in understanding and changing the situation, choosing strategic goals and tactical means. 
In connection with the situational approach, one often talks about the need for situational thinking. The characteristics of such thinking will be typical for any kind of effective thinking, which is analytical in its essence: flexibility, optimality, complexity, multifactority, non-standard (perhaps, although under great question). This only indicates that the very presence of a person, declared in a situational approach, makes the potential of formal logic schemes inadequate for its application. The situation is not rationalized by the old habitual means; it does not require formal classical logic, unable to grasp the change. Rather, it is the skills of dialectical logic with its emphasis on the birth of a new one. There is no person, there is no subject in the traditional logic. There is an impersonal scheme of action as a rule of unambiguous, impersonal forces. Therefore, we need some experience in the use of informal logics; it should be formed some certain, not just multi-valued, but valuable logic.

Setting question of the situational thinking and its formation can prove to be very useful for applying the situational approach in the private scientific knowledge and practice. After all, strictly speaking, the situationality is unlikely capable to dictate a list of specific actions, and it becomes more an art of manipulating factors, rather than the activity algorithm in this respect. However, the same is applied to the situational thinking, the flexibility of which can do without a rigid definition of concepts in the usual formal-logical understanding of it.

And the most important thing is that the situational approach should take into account a person, referring to him as the central link of situations. You may object to me: emphasis on the human role in the situation is typical for the spiritual situation analysis. And this objection is essential. After all, the subject of a specific analysis can be represented, for example, by the production situation. But does it, precisely as a situation, not include self-consciousness through and only through a person?

Does not it matter who is the person making the decision? This question does not cover only a limited technocratic approach. The analogy with the spiritual situation analyzed by Jaspers is quite appropriate here. Technological approach - knowledge of the organization structure, the factors of its development... teach this. They do not teach goal-setting, in which subjectivity implements itself in activity as a relation. They do not teach the experience of forming the ideas that go beyond the immediate problems, do not teach to be a person. Everyone becomes him by himself. Or he does not become.

\section{Results}

So, the analysis of possibilities of the situational approach as a cognitive method led us to the following conclusions. Not every situation can become a point of application of the situational methodology. Uncertainty, temporality and dynamism are important but inadequate characteristics of the situation to implement the situational approach as a methodological principle. A potential space of the situational ap- proach is the existing contradiction, crisis. There is always a person in the center of the situation, the crisis is connected with the non-implementation of its meanings, values, ideals. The situational analysis can be aimed at identifying these meanings, real values and goals. The very meanings, implemented in the goals, program future situations, linking time and place - the chronotope. Neither dynamism nor accident and lack of certainty should play the first fiddle in the situational methodology, but the integrity and historicity in the space-time game field of objective and subjective forces. Only a person can be a central player here. This, in turn, requires a revision of the investigator's thinking style, its orientation not to formal logic, but to a multi-valued logic of values.

\section{Conclusions}

Analysis of modern sources and contextual reading of K. Jaspers' work "Spiritual Time Situation" enables us to draw preliminary conclusions about the possibility of using situational methodology in the field of social research and social practice. The article takes initial approaches to creating the situational methodology, which requires further development.

\section{Acknowledgement}

The work is performed according to the Russian Government Program of Competitive Growth of Kazan Federal University.

\section{References}

[1] Cooper, W.H. The Strong Situation Hypothesis / W.H. Cooper, M.J. Withey // Personality and Social Psychology Review. 2009. Vol.13. No. 1. P. 62-72.

[2] Jaspers, K. Spiritual Time Situation (1932) / K. Jaspers / Translated by M.Levina // Meaning and Purpose of History / Karl Jaspers. - M.:Respublika, 1994, P. 288-418.

[3] Situational Dialogues. [Electronic resource] URL: http://nashol.com/2011040854303/situational-

dialogues-michael-ockenden.html (access date 29.07.17).

[4] Situational approach - the 21st century makes its own rules [Electronic resource] URL: http://http://tipings.com/en/pages/88877 (access date 29.07.17).

[5] Situational Researches. Issue 4: Situational Picture of the World / Edited by N. M. Solodukho. Under the InternationalScientific and Philosophical Conference. Kazan: Publishing House of the Kazan State Technical University, 2011. - 156 p.

[6] Marcolini P. Le Mouvementsituationniste: une histoire intellectuelle. - Paris. - 2012. - 337 p.

[7] Solodukho, N.M. Manifesto of the situational movement / N.M. Solodukho //The International Institute for Field-Being (IIFB). - Fairfield, USA, 2003, p. 42.

[8] Tereshchenko, N.A. Situationality of Situation / N.A. Tereshchenko // Situational Studies. Issue 3. Situation of Being. Under the International (CIS) Scientific-Philosophical Conference. Kazan: Publish- 
Helix Vol. 8(1): $2319-2323$

ing House of the Kazan State Technical University, 2011. - P. 56-66.

[9] Shatunova, T.M. Situation of Being and NonBeing Against the Non-Situation of Nothingness / T.M. Shatunova // Situation Researches. Issue 3. Situation of Being. Under the International (CIS) Scientific-Philosophical Conference. Kazan: Publishing
House of the Kazan State Technical University, 2011. - P. 15-23.

[10] VeklenkoPavel V. Situational Approach in the Social-Human Cognition: Objectives, Principles and Categories. Journal of Siberian Federal University. Humanities \& Social Sciences 5 (2015 8) 1003-1010 [Electronic resource] URL: elib.sfu-kras.ru (access date 29.07.17). 